\title{
Ayni: Por una infancia sin fronteras. Arteterapia con hijos de migrantes en el norte de Chile
}

Recibido: $31 / 03 / 14$

\author{
Jair MARÍN ALANIZ \\ Universidad de Tarapacá \\ Departamento de Filosofía y Psicología
}

Aceptado: $19 / 09 / 14$

\begin{abstract}
RESUMEN
El artículo presenta y analiza una selección de trabajos realizados por niños hijos de migrantes que residen en el norte de Chile. Los niños participan del Taller de Arteterapia Ayni, cuyo objetivo es ofrecerles un espacio de convivencia e integración. Los trabajos permiten comprender las condiciones de riesgo psicosocial que enfrentan los niños, así como la capacidad creativa que utilizan para salir adelante a pesar de la adversidad.
\end{abstract}

Palabras clave: Migración, familia, escuela, infancia, arteterapia.

\section{Referencia normalizada}

MARÍN ALANIZ, J. (2014). "Ayni: Por una infancia sin fronteras. Arteterapia con hijos de migrantes en el norte de Chile". En Arteterapia: Papeles de arteterapia y educación artística para la inclusión social Vol.: 9. Páginas 61-72. Madrid.

\begin{abstract}
The article presents and analyzes a selection of works by children of migrants residing in northern Chile. Children participate in Ayni Art Therapy Workshop, which aims to provide a space for coexistence and interaction. The works provide insight into the conditions of psychosocial risk children and the creativity they use to succeed despite facing adversity.
\end{abstract}

Keywords: Migration, family, school, children, art therapy.

\section{Introducción}

En las últimas décadas Chile ha recibido un importante número de migrantes, concentrándose el mayor índice en la frontera norte del país. Destaca de éste proceso la feminización de los flujos migratorios, pues el predominio lo obtienen las mujeres con un $53 \%$ frente a un $47 \%$ compuesto por hombres. Lo anterior se relaciona con el aumento en la llegada de niños hijos de migrantes, que componen el 15,34 \% de la población extranjera residente en el país (Ministerio del Interior, 2009). Según algunas recientes investigaciones (Tapia y Ramos, 2013; Marín et al., 2014), el número de migrantes que se establecen en el norte de Chile,

\footnotetext{
${ }^{1}$ Universidad de Tarapacá. Departamento de Filosofía y Psicología. jair.marin.alaniz@gmail.com. Psicólogo, Magister en Ciencias Sociales Aplicadas. Director Diplomado en Educación Intercultural y Migración Latinoamericana - Universidad de Tarapacá. Coordinador y arteterapeuta del Taller de Arteterapia Ayni.
} 
junto a la feminización de estos flujos correspondería a una tendencia que sigue en aumento.

Indicadores que resultan relevantes pues algunas investigaciones dan cuenta de que precisamente las mujeres y sus niños serían quienes sufren mayores riesgos durante los procesos migratorios (Stefoni et al., 2008). No obstante, los estudios sobre la situación de los hijos de migrantes en Chile es bastante limitada, si bien destacan valiosos trabajos (Poblete, 2006; Stefoni, 2008; Pavez, 2010; Tijoux, 2013), los estudios sobre la infancia de la migración en el país aún son escasos. Lo que resulta preocupante al corroborar que las familias migrantes que llegan a Chile encuentran un contexto de pobreza que se hace evidente en los trabajos precarios a los que logran acceder. Factor que les impediría gozar de servicios sociales de calidad, poniéndose en riesgo el bienestar de toda la familia.

Las limitaciones económicas se relacionarían directamente con la calidad educativa que reciben los hijos, en este sentido, Stefoni et al. (2008) ponen en evidencia una serie de mecanismos informales, directamente influidos por xenofobia y discriminación, que obstaculizarían los procesos de inserción de los hijos de migrantes a sus nuevas escuelas. Por tanto, el proceso de integración de estos niños y niñas al sistema educacional estaría determinado por el perfil socioeconómico de sus familias. Como resultado, las oportunidades educativas a las que acceden contribuirían a la reproducción y consolidación de la desigualdad social.

Los hijos de migrantes acuden mayormente a las escuelas públicas, sin embargo, en estas instituciones la diversidad cultural no sería valorada como una oportunidad de desarrollo, pues por el contrario supondría un nuevo problema que se suma a las dificultades ya existentes. La ausencia de programas de acogida, desembocaría en prácticas discriminatorias y de estigmatización. Por ejemplo, los niños viven algunas de estas situaciones cuando sus profesores interpretan erróneamente las diferencias curriculares o lingüísticas, y las identifican como un problema para el avance de la clase (Pavez, 2010).En consecuencia, para los hijos de migrantes la interpelación desde el origen pareciera vivirse como un señalamiento o una marca (Novaro, 2011). Junto a lo anterior, se presentan problemas de convivencia entre los alumnos chilenos y los alumnos extranjeros, pues es posible identificar que los alumnos extranjeros sufrirían acciones discriminatorias sustentadas en la valoración racista de sus tonos de piel (Tijoux, 2013).

Ante ésta dramática situación surge en el año 2011 "Proyecto Ayni: Por una Infancia sin Fronteras", , que interviene con talleres de arteterapia en las escuelas con mayor número de matrícula migrante de ciudad de Iquique, ubicada al norte de Chile. Estos talleres surgen como una oportunidad para alcanzar una sociedad que apuesta por la diversidad, la igualdad y la tolerancia. Éste es el punto neurálgico de esta iniciativa que nace del concepto "Ayni”, palabra Aymara que signi-

\footnotetext{
${ }^{2}$ Iniciativa reconocida con el Premio ACCIÓN JOVEN 2013 de la International YouthFoundation y la Universidad Andrés Bello.
} 
fica "trabajo en reciprocidad". Por tanto, el presente artículo recoge la experiencia acumulada durante estos años trabajando con los niños hijos de migrantes.

Para facilitar la lectura, el documento parte con la definición de los principales conceptos que sustentan la intervención, luego se presentan los objetivos del taller y la metodología utilizada. Continuando, se expone una selección de los trabajos desarrollados por los niños y le sigue una discusión sobre los resultados más significativos. Para finalizar se presenta una breve conclusión y algunas sugerencias para trabajar con los hijos de migrantes en las escuelas.

\section{Migración, familia y escuela: articulaciones desde el arteterapia}

La migración es un fenómeno inherente a la naturaleza humana, pues desde siempre el hombre se ha caracterizado por trasladarse en busca de mejores alternativas de vida. Sin embargo, si bien la migración es un fenómeno global tan antiguo como la historia de la humanidad, desde hace varias décadas hemos asistido al crecimiento significativo de la migración internacional. Entre los motivos que explicarían este crecimiento se encuentran las expectativas de mejores oportunidades laborales, la reducción en el costo del transporte, el uso de las redes online y los enclaves migrantes establecidos en los países de destino (Marín et al., 2014).Ahora bien, es importante señalar que más que por voluntad, la migración surgiría como una necesidad debido a los problemas sociales, políticos y económicos, además de desastres naturales que enfrentan los países. En consecuencia, constituiría una elección forzada.

En tales términos, la migración supondría uno de los procesos de cambios más complejos que enfrentan las familias, pues representa un evento estresante que transformaría la estructura familiar. En ese sentido, algunas investigaciones dan cuenta que frecuentemente la experiencia migratoria se apoderaría del bienestar psicológico de la familia, quedando sus miembros expuestos al riesgo de sufrir depresión, angustia y desordenes psicosomáticos (Achotegui, 2002).

Ligado a lo anterior, la feminización de los flujos migratorios asociada a la apertura del mercado laboral para las mujeres, es una de las principales características que destaca en las últimas décadas. Esta feminización favorecería las posibilidades para la reunificación familiar, pues la maternidad es valorada por las mujeres como un rol fundamental, lo que en consecuencia acelera la llegada de sus hijos (Stefoni et al. 2008)

Ahora bien, Suarez - Orozco y Suarez- Orozco (2003) señalan que la migración podría acarrear vivencias traumáticas para los niños, lo que afectaría negativamente en cómo experimentan la infancia. No obstante, si bien la migración supondría grandes cambios y pérdidas, también ofrecería oportunidades y desafíos. Al respecto Pavez (2010) sostiene que los niños migrantes son verdaderos agentes sociales, con capacidad de reflexión y participación. Según la autora, los niños son sujetos que transformarían los entornos que habitan, por tanto, los define como actores sociales claves capaces de incidir en el proyecto migratorio familiar. En tal contexto, el principal escenario donde los niños se enfrentan al nuevo entorno cultural es en la escuela. 
La escuela es una institución relativamente reciente de la modernidad, relacionada con la consolidación de los Estados nacionales y formalmente encargada de la transmisión de conocimientos a las nuevas generaciones. Supone la especialización institucional y la existencia de dispositivos específicos para cumplir funciones determinadas. Ahora bien, los sujetos se educan en otras instancias además de las escuelas, pues el concepto de educación es mucho más amplio que la escolarización (Levinson y Holland, 1996). Sin embargo, históricamente la escuela ha intentado imponerse a los otros espacios formativos y esto se relaciona con el sostenido trabajo de auto-legitimación.

Por tanto, la escuela se entiende como una instancia privilegiada y sostenida de educación sistémica, como espacio institucional de instrucción intencional, que ha sido legitimado en la modernidad como dispositivo educativo hegemónico, ya que si bien lo hegemónico no lo incluye todo, si lo permea todo. Consiguientemente, sabemos que la escuela no tiene el monopolio de la formación de los sujetos en una sociedad determinada, pero también sabemos que no podemos entender acabadamente estos procesos formativos sin aludir a la escolaridad (Novaro, 2011).

Sánchez y Zúñiga (2010) sostienen que las escuelas son instituciones que estarían conformadas para responder a los fines de los Estados nacionales, por ello la diversidad cultural desplegada en los espacios escolares, supondría en muchas ocasiones un riesgo para la identidad nacional instaurada y sostenida por el Estado. A pesar de ello, es posible observar algunas acciones orientadas al reconocimiento de los derechos de los pueblos indígenas y otros grupos considerados "diversos", como los migrantes. Esto se observa en manifestaciones de valoración acrítica de la diversidad, asociado a estrategias de visibilización y en ocasiones de hipervisibilización. No obstante, frecuentemente dichas manifestaciones terminarían siendo una forma de violencia, pues el mandato de autoafirmación se transformaría en una marca, asociada a una carencia o una falta, que los niños en contextos escolares en ocasiones no desean asumir o explicitar (Novaro, 2011).

En síntesis, es en las escuelas donde los hijos de migrantes se verían enfrentados a la integración y adquisición de nuevas pautas de aprendizaje y comportamiento, de ahí la importancia de trabajar en estos establecimientos. Frente a ello, una de las principales herramientas con la que se puede trabajar la diversidad en la escuela es el Arteterapia, la que se define como una especialización profesional que emplea la expresión plástica como medio de comunicación, contribuyendo a la exploración y elaboración del mundo interno de las personas durante el proceso terapéutico (Asociación Chilena de Arte Terapia ACAT, en Grosser, 2007).

El Arteterapia posibilita un acceso lúdico y poco invasivo al auto-concepto, permitiendo reconocer determinados conflictos y favoreciendo una mayor clarificación emocional. La obra plástica se transforma en un reflejo del proceso terapéutico y alimenta el análisis, la comparación y la discusión. Asimismo, desarrolla herramientas como la creatividad, para resolver problemas internos y externos, 
favorece la autoestima y una mejor comunicación, desencadenando un mayor desarrollo personal (Grosser, 2007).

Esta disciplina promueve también la resiliencia, definida como la capacidad de desenvolverse adecuadamente de acuerdo a las etapas de desarrollo y lograr salir adelante a pesar de la adversidad (Kotliarenco, 1997).De ahí la importancia de trabajar desde el arte con los hijos de migrantes como una alternativa de apoyo ante las fuertes presiones sociales a las que están expuestos y que atentan contra su bienestar.

\section{Objetivos del taller}

- Otorgar un espacio seguro para trabajar sobre las necesidades de los niños participantes.

- Fomentar en el grupo relaciones de convivencia colaborativa y orientadas a la valoración positiva de la diversidad cultural.

- Contribuir en el descubrimiento de sus herramientas psicosociales para el desarrollo personal.

\section{Metodología}

Participan del taller niños hijos de migrantes provenientes de Perú, Bolivia, Ecuador y Colombia, así como niños chilenos, pues justamente se intenta fomentar la integración. La edad de los participantes fluctúa entre los 7 y 12 años.

Los talleres se realizan en las escuelas durante las tardes, una vez que los niños terminan su jornada escolar. Los grupos de trabajo se componen de un máximo de 5 miembros, los que son orientados por un arteterapeuta.

Las técnicas utilizadas son el dibujo, la pintura, el reciclaje y el collage. Una vez que los niños terminan sus trabajos, deben exponerlo al resto del grupo, generando un espacio para la retroalimentación y el diálogo constructivo.

Respecto a los aspectos éticos, antes de integrarse al taller se solicita la autorización a los padres, señalándoles que algunas discusiones podrían ser grabadas en formato audio y sólo con fines investigativos, pero que sin embargo, la identidad de los niños será resguardada en todo momento.

\section{Resultados}

A continuación, se presenta una selección de cinco trabajos que muestran de modo general el proceso de desarrollo en los talleres. La elección de los trabajos responde al carácter representativo de cada obra, pues contribuyen a comprender las experiencias que atraviesan los niños durante el proceso migratorio. Junto a las imágenes de las obras se presentan algunos extractos de los testimonios de los alumnos al presentar sus trabajos, los que fueron grabados en formato audio como se señala en el apartado de la metodología.

Cruce fronterizo 


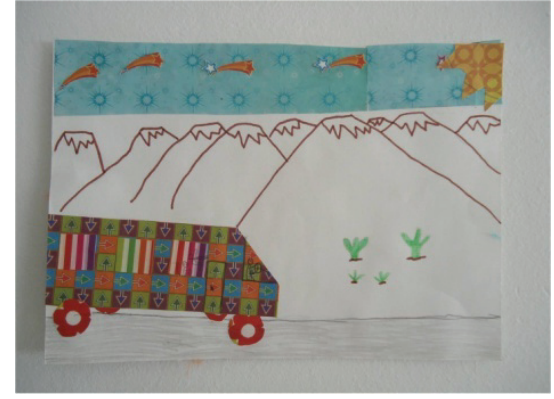

Fig. 1. Cruce fronterizo.

El trabajo corresponde un niño boliviano, y grafica su viaje desde a Bolivia hasta Chile. Según su relato el viaje fue impresionante, pues por primera vez salía de la zona rural donde vivía al interior de la ciudad de Santa Cruz de la Sierra. De las ciudades por donde pasó, llamaron su atención las personas que vivían en la calle: "Había unos señores que dormían en la calle, en mi pueblo no era si". Por otro lado, le sorprendió positivamente el paso por la Cordillera de los Andes: " $L a$ cordillera estaba fría, pero a mi me gusta, es diferente, nunca había visto cerros tan grandes". No obstante, al llegar a la frontera su experiencia se torno negativa, pues durante la madrugada los recintos fronterizos cierran sus puertas y lo viajeros deben esperar dentro de los autos en medio del altiplano, soportando temperaturas extremas: "Lo malo fue que tuvimos que esperar re harto rato, y ahi me dio mucho, pero mucho frío, mi mamá me puso una mantita, pero tenía más frio”.

Dificultades familiares:

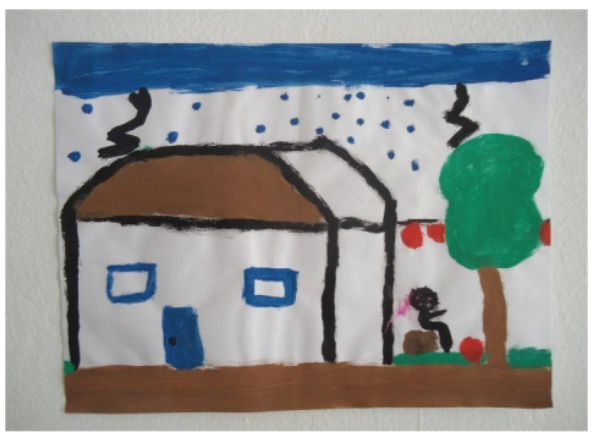

Fig. 2. Dificultades familiares.

La pintura pertenece a un niño ecuatoriano y hace referencia a su familia. Distingue la figura solitaria de un niño fuera de la casa, la cual fue dibujada con trazos oscuros y gruesos, siendo la puerta y las ventanas muy pequeñas. Sobre la casa destaca una gran tormenta, gruesas gotas y un par de rayos. Al ser consultado por su dibujo, el niño señaló que se sentía muy sólo, pues, junto a su madre y su hermana, dejaron su país escapando de un padre abusador: "Una navidad mi padre se emborrachó y peleó con mi mamá, entonces se enojó y nos sacó de la casa, entonces nomas tuvimos que pasar la noche en la plaza debajo de un árbol". Si bien al establecerse en Chile se libraron de la violencia que ejercía el padre, ahora el bienestar familiar se ponía en jaque debido a las condiciones de riesgo social: "Mi mamá trabaja en la noche allá en un bar, y cuando llega en la mañana tiene mucha hambre, entonces nosotros nos venimos a la escuela. Pero cuando no venimos a la escuela no podemos almorzar, entonces siempre vengo". El sobrecogedor relato da cuenta de la compleja situación social por la que atraviesan muchos 
alumnos migrantes, los que frecuentemente enfrentan situaciones que vulneran sus derechos.

Discriminación en la Escuela

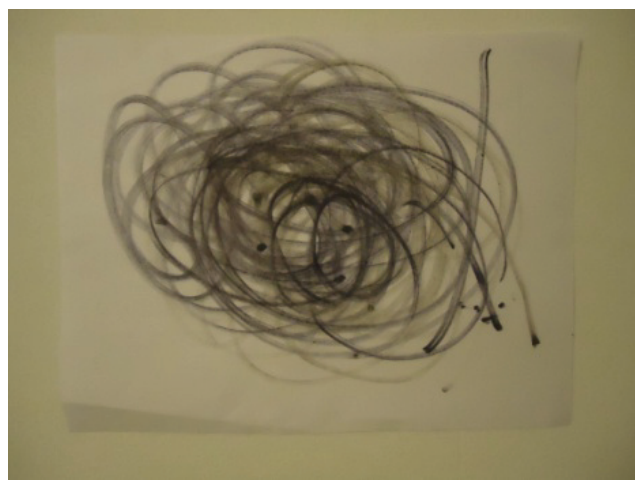

Fig. 3. Discriminación en la Escuela.
En este trabajo un niño peruano grafica las situaciones de discriminación que sufre en su escuela:"Asi me siento en la sala, cuando me molestan es como un torbellino y yo soy un punto ahi al medio, no me gusta. Me parece que la escuela es linda, pero sería mejor si no hubiera unos niños que me molestan, son idiotas. Algunas niñas son malas, se creen la gran cosa y me pegan". Lo anterior corresponde a situaciones cotidianas que atraviesan los niños en sus escuela y evidencian las condiciones de vulnerabilidad que enfrentan: "Cuando estamos jugando nos quitan la pelota, que no nos quiten la pelota y que los niños más grandes no nos peguen”. Finalmente, al consultar a que atribuye el maltrato que recibe de sus compañeros, el niño responde: "No sé, yo le dije a mi mamá, pero yo creo que como soy peruano a ellos no les agradan los peruanos. También allá en mi curso hay niños que molestan a dos peruanos les dicen pe".

Resiliencia

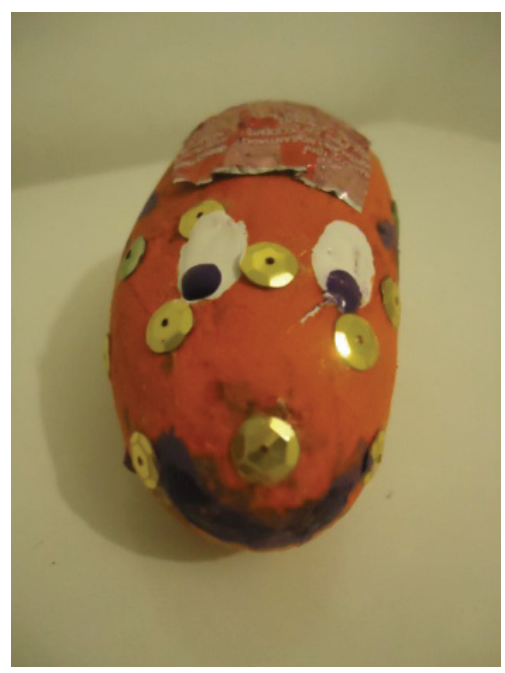

Para confeccionar éste trabajo, los niños recolectaron diversos materiales desde el patio la escuela y luego junto a los materiales que les entregaban los arteterapeutas debían crear una figura que los representara. De todos los trabajos destacó la obra de un niño boliviano, quien recolectó una piedra y algunos envases de pastillas, y con ellos creó un ratón. Al ser consultado por su trabajo señaló: "Este ratón soy yo, es que casi siempre juego sólo y no me gusta estar jugando con los pegones, pero yo igual lo paso bien en los recreos y juego por los rincones aunque nadie me vea, como un ratón". La obra refleja la resiliencia y la capacidad creativa del niño, pues a pesar de la complejidad del contexto social al que está

Fig. 4. Resiliencia 
expuesto, logra desarrollar una estrategia que le permite disfrutar y alcanzar un momento de satisfacción.

\section{Escuela ideal}

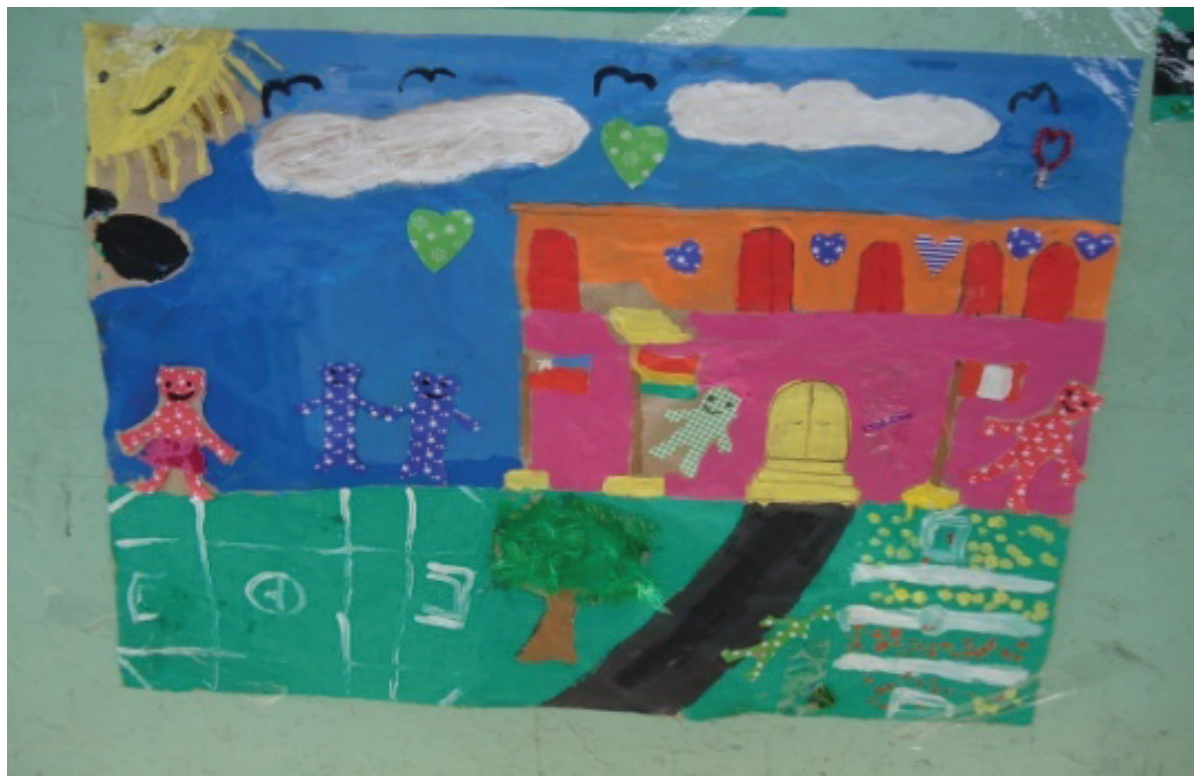

Fig. 3. Discriminación en la Escuela.

El cuadro corresponde al trabajo de finalización de uno de los talleres. Para su realización se les indicó a los niños que debían pintaren equipo un cuadro que representara la escuela ideal a la que les gustaría asistir. Como resultado se observa una escuela donde los niños se ven alegres, el sol luce radiante, destacan las áreas verdes y un edificio muy colorido, dentro del cual conviven banderas de diferentes países. Este trabajo se podría entender como un antónimo de la realidad presente en las escuelas, pues a partir de los trabajos anteriormente expuestos es posible identificar que las escuelas representan un contexto propicio para la exclusión. Al describir la obra una niña señaló: "Despediría a los niños que molestan, a las choritas y crearía más juegos". Otro niño replicó: "Si hay niños peleando los voto de acá y los voto en su casa". Para finalizar, en referencia a las banderas un niño declaró: "Ser chileno, ser peruano o ser boliviano es lo mejor, porque todos los países son bacanes" ${ }^{4}$.

\footnotetext{
${ }^{3}$ Modismo chileno que se refiere a una persona peleadora.

${ }^{4}$ Modismo chileno que se refiere a algo excelente.
} 


\section{Discusión}

Respondiendo al primer objetivo planteado, es posible señalar que el taller efectivamente constituye un espacio seguro para trabajar sobre las necesidades de los niños. Lo anterior se relaciona con que el establecimiento de este espacio de confianza permite acceder a las vivencias de los participantes, para comprender sus necesidades.

Entre estos hallazgos destaca la experiencia del cruce por la frontera, pues está teñida por episodios negativos que ponen en riesgo su bienestar, con esto nos referimos a la exposición a temperaturas extremas que enfrentó el niño boliviano en la Cordillera de los Andes, aguardando a la apertura del reciento fronterizo. Esto se relaciona con lo señalado por algunos estudios que sostienen que los niños viven el cruce de la frontera como un episodio traumático (Suarez - Orozco y Suarez Orozco, 2003).

Sobre la situación familiar, el trabajo seleccionado refleja muy bien las condiciones de vida que enfrentan las familias migrantes. Aparecen episodios de violencia intrafamiliar que se suman a los obstáculos que experimentan en el nuevo país de destino. La precariedad laboral de los padres, la desprotección social y el hacinamiento atentan contra las familias y particularmente contra sus hijos. En este sentido, Tijoux (2013) sostiene que el limitado marco legislativo, posibilita que algunos empleadores abusen de los trabajadores migrantes y en consecuencia se construya una imagen social negativa en torno a ellos.

Las consecuencias de la discriminación hacia los migrantes la padecen directamente sus hijos, y las escuelas constituyen el principal escenario donde se expresan éstas prácticas. Impresiona el testimonio del niño peruano que relata los episodios de violencia que sufre cotidianamente, atribuyendo el maltrato a su origen nacional. Desafortunadamente corresponde a una realidad muy presente en las escuelas chilenas y de esto dan cuenta Stefoni et al. (2010), quienes destacan la segregación que sufren los hijos de migrantes por parte de las instituciones escolares, los profesores y los compañeros.

Según Novaro (2011), frente al maltrato cotidiano recibido en sus escuelas, los hijos de migrantes desarrollan diversas estrategias, a veces responden a la violencia con más violencia con el objetivo de conseguir el respeto de sus compañeros. Otras veces los niños parecen tímidos, observadores y muy temerosos, intentado ser invisibles y de algún modo evitar la violencia. Sin embargo, estas conductas los vuelven más vulnerables psicológicamente y obstaculizan el proceso de integración.

En cuanto al segundo objetivo que persigue contribuir en el descubrimiento de las herramientas psicosociales para el desarrollo personal, es posible señalar que si bien la migración puede resultar traumática cuando el prejuicio y la discriminación se posicionan, algunos niños muestran una valerosa actitud resiliente frente a sus circunstancias. Por medio de la creatividad los niños logran generar espacios de resistencia que les permiten afrontar las dificultades cotidianas. Esto se refleja en la obra del ratón creada por el niño boliviano, que resulta conmovedora por la ternura con que el niño supera la soledad y la exclusión. 
Respecto al último objetivo, dirigido a fomentar en el grupo relaciones de convivencia colaborativa y orientadas a la valoración positiva de la diversidad cultural, destaca la obra denominada "Escuela ideal", pues pone en valor el punto de vista de los niños respecto a cómo mejorar la convivencia dentro de la escuela a través de la integración. En este sentido, el arteterapia permite rescatar el rol de los niños como agentes de cambio capaces de transformar sus condiciones de vida y las de su entorno social.

Ante al aumento de matrícula migrante, algunas escuelas han comenzado a promover actividades de reconocimiento de las culturas extranjeras por medio de eventos escolares donde se exponen danzas y comidas típicas. No obstante, en la practica el sistema educacional chileno presenta una notable ausencia de programas acogida e integración orientados a los alumnos extranjeros (Pavez, 2010). Por tanto, el trabajo que incluya a toda la comunidad educativa se vuelve una tarea urgente, para evitar el estigma y la reproducción de imágenes negativas que recaen sobre los migrantes. Es ahí donde se abre el espacio para la educación intercultural, pues constituye una excelente herramienta para generar espacios de convivencia y aceptación de la diversidad (Poblete, 2006).

\section{Conclusión}

A partir de los trabajos seleccionados podemos concluir que los niños participantes experimentan el proceso migratorio con mucha intensidad. Lo anterior se desprende de las situaciones de exclusión que padecen a largo del proceso migratorio. Es decir, el cruce por la frontera, las condiciones de vulnerabilidad social que afecta a sus familias y los episodios de discriminación sufren en sus nuevas escuelas.

No obstante, pese a las múltiples experiencias negativas asociadas a la migración, los niños logran desarrollar estrategias creativas que les permiten sobreponerse a las dinámicas de segregación presentes en el ámbito escolar. Asimismo, el taller pone de manifiesto el punto de vista de los niños respecto a cómo generar mayor integración y aceptación en la escuela, así como sus opiniones críticas respecto a la discriminación.

Los resultados de esta investigación permiten comprender la urgencia de alcanzar una mayor inclusión social dentro de las instituciones escolares. Por lo que se recomienda trabajar con toda la comunidad educativa poniendo énfasis en la participación de los niños, con el fin de modificar la representación negativa respecto a los migrantes y comenzar a valorar positivamente la diversidad cultural. En esta línea el trabajo con arteterapia representa un excelente punto de partida, pero se debe consolidar con programas y políticas de acogida apoyadas desde el Estado y que permitan un currículo escolar más abierto a las nuevas realidades presentes en la sociedad chilena.

Finalmente, si los niños hijos de migrantes lograrán superar el desafío de la integración en las escuelas chilenas, sólo el tiempo lo dirá. En lo que respecta a los arteterapeutas, resta cumplir la misión de seguir estableciendo espacios para 
la creatividad, la tolerancia y la sana convivencia, con el noble objetivo de alcanzar una infancia sin fronteras.

\section{Referencias bibliográficas}

ACHOTEGUI, J. (2002). La depresión en los inmigrantes: una perspectiva transcultural. Barcelona, Ediciones Mayo.

GROSSER, H. (2007). El embarazo como un renacer. Una intervención de Arte Terapia en una mujer embarazada víctima de violencia intrafamiliar. Proyecto Final para optar al Curso de Especialización de Postítulo en Terapias de Arte, mención Arte Terapia. Universidad de Chile. Disponible en: $<$ http://www.tesis.uchile.cl/tesis/uchile/2007/grosser_h/sources/grosser_h.pdf $>$

KOTLIARENCO, M. (1997). Estado del arte en resiliencia. Santiago, Organización Panamericana de la Salud.

LEVINSON, D. \& HOLLAND, D. (1996).Thecultural production of the educated person. New York, State University of New York Press.

MARÍN, J., GUTIÉRREZ, F., Y MARÍN, R. (2014). "Uso de redes online y familias transnacionales en el norte de Chile: Desafíos para la comunicación". En Punto Cero, 28, 9-16.

MINISTERIO DEL INTERIOR. (2009). Informe anual de extranjería y migración gobierno del interior. Santiago, Ministerio del Interior.

NOVARO, G. (2011). La intercultural en debate. Buenos Aires, Biblos.

PAVEZ, I. (2010). "Los derechos de las niñas y los niños peruanos en Chile: la infancia como un nuevo actor migratorio". En Enfoques, 12, 8,27-51. Disponible

en: $<$ http://www.politicaygobierno.cl/documentos/enfoques/12/art_Iskra_Pave z.pdf $>$

POBLETE, R. (2006). Educación Intercultural: teorias, políticas y prácticas. La migración peruana en el Chile de hoy. Nuevos escenarios y desafios para la integración. Tesis de Doctorado. Universidad Autónoma de Barcelona, España. Disponible en: http://ddd.uab.cat/pub/tesis/2006/tdx-1203107163314/rpm1de1.txt

SÁNCHEZ, J. Y ZÚÑIGA, V. (2010). "Trayectorias de los alumnos transnacionales en México. Propuesta intercultural de atención educativa". En Trayectoria Universidad Autónoma de Nuevo León, 12, 5-33.

OROZCO, C. Y SUÁREZ - OROZCO, M. (2003). La infancia de la inmigración. Madrid, Morata.

STEFONI, C., ACOSTA, E., GAYMER, M., Y CASAS- CORDERO, F. (2008). Niñas y niños inmigrantes en Santiago de Chile. Entre la integración y la exclusión. Santiago, Universidad Alberto Hurtado y OIM. Disponible en: $<$ http://www.ucentral.cl/prontus_ucentral/site/artic/20100722/asocfile/201007 
22182134/ninos_y_ninas_inmigrantes_en_santiago_de_chile_entre_la_integ racion_y_la_exclusion.pdf $>$

TAPIA, M. Y RAMOS, R. (2013), "Mujeres migrantes fronterizas en Tarapacá a principios del siglo XXI. El cruce de las fronteras y las redes de apoyo". En Revista Polis, 35. Disponible en: <http://polis.revues.org/9321;DOI : $10.4000 /$ polis. $9321>$

TIJUOX, M. (2013). "Niños (as) marcados por la inmigración peruana: estigma, sufrimientos, resistencias". En Convergencia, Revista de Ciencias Sociales, 61, 83-104.Disponible en:

http://www.redalyc.org/articulo.oa?id=10524674004, 4-355.

Agradecemos el apoyo del Convenio de Desempeño UTA - MINEDUC. 